\title{
Pulmonary hyalinising granuloma in association with retroperitoneal fibrosis
}

\author{
RG DENT, DJ GODDEN, PGI STOVIN, JE STARK \\ From the Chest Unit, Papworth Hospital, Cambridge
}

Pulmonary hyalinising granuloma is an unusual condition of unknown aetiology, which has not previously been reported in Britain. We report such a case, occurring in association with retroperitoneal fibrosis.

\section{Case report}

The patient, aged 36 years, was referred in 1968 after discovery of a discrete mass $1 \mathrm{~cm}$ in diameter in the right lower lobe on a routine chest radiograph. The lesion was thought to be a healed primary tuberculous focus, and he was reviewed annually until 1974 , when the lesion was noted to be enlarging. Thoracotomy was performed and three nodules were excised from the right lower lobe.

The specimen consisted of two pieces of focally thickened visceral pleura, with three subjacent firm fibrocalcareous nodules $1.2-1.4 \mathrm{~cm}$ in diameter. Histological examination showed that they were composed of densely matted and stout, poorly cellular collagen fibres with a fine granular stippling with calcium salts. At the periphery there were plasma cells between collagen fibres and sparse pale pink sudanophilic droplets indicative of mineral oil (fig 1); these had not excited a giant cell reaction. Yellow green dichroism was seen when Congo red stained sections were examined under polarised light, indicating the presence of amyloid within these nodules.

In 1978 the patient developed low back pain and an intravenous urogram showed medial deviation of the ureters suggestive of retroperitoneal fibrosis. The erythrocyte sedimentation rate (ESR) was $45 \mathrm{~mm}$ in the first hour; an autoantibody screen was negative; and $\mathrm{C} 3, \mathrm{CH} 50$, and immune complexes were in the normal range. His symptoms improved after prednisolone treatment, but in 1980 he became hypertensive and bilateral ureterolysis was performed. Tissue removed at operation showed dense, poorly cellular collagen bundles (fig 2). Unlike the pulmonary nodules, this focus of retroperitoneal fibrosis had no demonstrable amyloid or calcium.

In 1981, in view of continuing hypertension, treatment with hydrallazine $25 \mathrm{mg}$ three times daily was started. Fourteen months later he developed a left pleural effusion. Pleural aspiration showed an amber coloured exudate containing mesothelial cells, histiocytes, lymphocytes and eosinophils; lupus erythematosus cells were seen. Exami-

Address for reprint requests: Dr RG Dent, Papworth Hospital, Papworth Everard, Cambridge CB3 8RE.

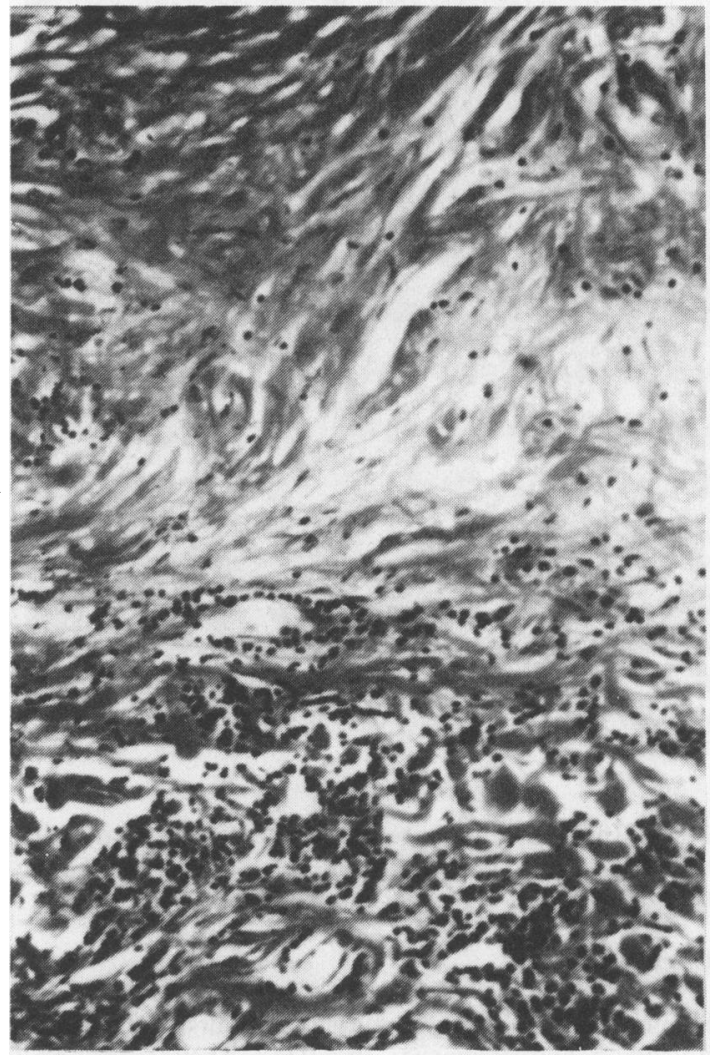

Fig 1 Lung nodule showing stout collagen bundles and the lymphocytic and plasma cell infiltration at the edge of the lesion. (Haematoxylin and eosin, $\times 200$.)

nation of pleural biopsy specimens showed fibrin on the surface of pleura minimally thickened by fibrous tissue with a lymphocytic reaction in the adventitial border. At this time the rheumatoid arthritis latex test and the antinuclear factor test gave negative results and the serum thyroid microsomal antibody titre was $1 / 25$. The effusion resolved without treatment and the patient remains well. According to recent investigations the ESR is $30 \mathrm{~mm}$ in one hour and there is a polyclonal increase in serum IgG, with total IgG $15.4 \mathrm{~g} / \mathrm{l}$, antinuclear factor $1 / 25$, thyroid microsomal antibody $1 / 1600$, and thyroglobulin antibody 


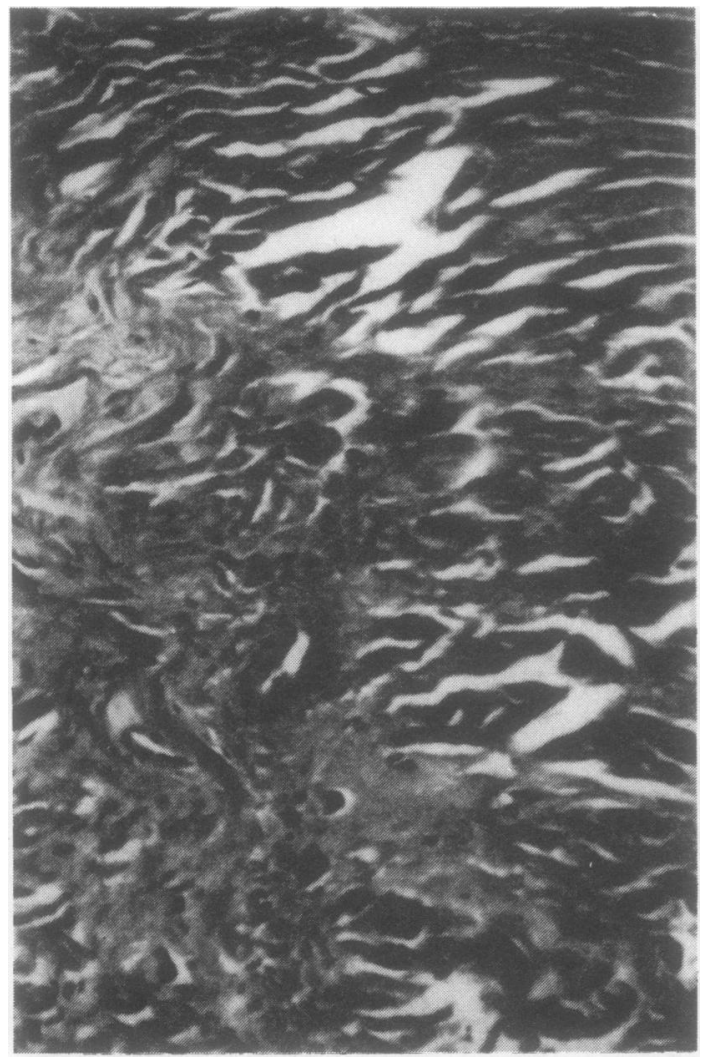

Fig 2 Retroperitoneal fibrosis: stout collagen bundles with very few fibrocytes present. (Haemotoxylin and eosin, $\times 200$.)

1/160. Tests for other organ specific antibodies have given negative results. Immune complexes ( $24 \%$ by PEG consumption) are at the upper limit of the normal range.

\section{Discussion}

Pulmonary hyalinising granuloma was first described by Engleman and colleagues in 1977.' They reported 20 patients, both male and female, with ages ranging from 27 to 66 years. Symptoms included cough, pleuritic chest pain, and haemoptysis, though some were symptom free. Four of their patients had associated sclerosing mediastinitis and one had retroperitoneal fibrosis. Lesions, which could be single or multiple and unilateral or bilateral, were found to enlarge and regress spontaneously and no aetiological agent was identified. The histological appearances of our patient's lesions were originally attributed to his inhalation of oil from an industrial explosion. The mineral oil droplets, however, were free in the collagen or were within macrophages, and no foreign body giant cells were seen. While these droplets may have produced the fibrosis, this seems unlikely in view of the relative sparsity of the droplets compared with the amount of fibrosis and the absence of giant cells. It could be argued that any mineral oil might act as a Freund type adjuvant to the main fibrogenic stimulus, but this also seems unlikely.

The condition remains rare, and in a recent series ${ }^{2}$ accounted for only two of $\mathbf{8 6}$ solitary granulomas. It has been proposed that the condition represents an abnormal immune response to unknown stimuli, and two patients have been described ${ }^{3}$ in whom autoantibodies were detected, together with circulating immune complexes. Our patient has developed autoantibodies-though the role of hydrallazine in his case is not clear, and this drug is being withdrawn. The association of retroperitoneal fibrosis with sclerosing mediastinitis is well recognised, and more recently a case of lymphomatoid granulomatosis with retroperitoneal fibrosis has been described. ${ }^{5}$ It seems likely that pulmonary hyalinising granuloma is indeed a feature of a disordered immune response, and may form part of a range of conditions along with these others. In practical terms, hyalinising granuloma requires consideration in the differential diagnosis of solitary or multiple pulmonary nodules.

\section{References}

' Engleman P, Liebow AA, Gmelich J, Friedman PJ. Pulmonary hyalinising granuloma. Am Rev Respir Dis 1977;115:9971008.

${ }^{2}$ Ulbright TM, Katzenstein ALA. Solitary necrotising granulomas of the lung. Am J Surg Pathol 1980;4:13-28.

${ }^{3}$ Schlosnagle DC, Check IJ, Sewell CW, Plummer A, York RM, Hunter RL. Immunologic abnormalities in 2 patients with pulmonary hyalinising granuloma. Am J Clin Pathol 1982;78:231-5.

4 Hawk WA, Hazard JB. Sclerosing retroperitonitis and sclerosing mediastinitis. Am J Clin Pathol 1959;32:321-34.

' Hammar SP, Gortner D, Stanford S, Bockus D. Lymphomatoid granulomatosis: association with retroperitoneal fibrosis and evidence of impaired cell-mediated immunity. Am Rev Respir Dis 1977;115:1045-50. 